\title{
Proteomic Quantification Method
}

National Cancer Institute

\section{Source}

National Cancer Institute. Proteomic Quantification Method. NCI Thesaurus. Code C161810.

A method applied to a proteomics study in order to quantify the experimentally-collected data. 